\title{
Climatology of Tropical Overshooting Tops in North Atlantic Tropical Cyclones $\mathscr{O}$
}

\author{
SARAH M. GRIFFIN \\ Cooperative Institute for Meteorological Satellite Studies, University of Wisconsin-Madison, \\ Madison, Wisconsin
}

(Manuscript received 21 December 2016, in final form 20 April 2017)

\begin{abstract}
Organized tropical convection, often characterized by overshooting tops, is a distinguishing quality of tropical cyclones (TCs). In this study, the climatology of tropical overshooting tops (TOTs) in North Atlantic Ocean TCs from 2004 to 2015 is examined. Previous studies have investigated the distribution of convection in TCs based on lightning data. The purpose of this study is to examine the distribution of TC convection from geostationary satellites using an objective TOT detection algorithm based on infrared brightness temperatures and empirically dependent thresholds. It will be shown that TOTs can provide an additional metric for identifying the characteristics of TC convection. Based on the 12-yr (2004-15) climatology, a distinct semidiurnal cycle in TOT activity is detected within $500 \mathrm{~km}$ of the TC center. In agreement with lightning data from previous studies, a predawn maximum (local to the TC) in TOTs is observed within $300 \mathrm{~km}$ of the TC center. A second predusk maximum is associated with TOTs between 300 and $500 \mathrm{~km}$ of the TC center. TC intensity and intensity trend along with environmental factors can affect the number and distribution of TOTs. For example, an exponential relationship exists between the number of TOTs and increasing sea surface temperatures. Conversely, increasing vertical wind shear magnitude decreases the density of TOTs, with a higher percentage of TOTs observed downshear of the wind direction. Generally, within $100 \mathrm{~km}(100-300 \mathrm{~km})$ of the TC center, the preferred quadrant for TOTs is downshear left (downshear right), and increased TOT activity is observed right of TC motion. The findings corroborate previous lightning study results while providing additional insights into TC convection.
\end{abstract}

\section{Introduction}

Important aspects of tropical cyclone (TC) current and future intensity can be derived from the vigor and distribution of convection around the storm. Because of the overocean nature of TCs, many studies have used satellite data to estimate the current TC intensity (Dvorak 1975; Velden et al. 2006) as well as predict future TC intensity (Steranka et al. 1986; Olander and Velden 2009). One satellite-based method for identifying particularly active TC convection, tropical overshooting tops (TOTs), is skillful at predicting TC rapid intensification (Monette et al. 2012). Therefore, it is important to document the distribution and behavior of TC convection under different environmental conditions.

\footnotetext{
O) Supplemental information related to this paper is available at the Journals Online website: http://dx.doi.org/10.1175/ JAMC-D-16-0413.s1.
}

\footnotetext{
Corresponding author: Sarah M. Griffin, sarah.griffin@ssec.wisc.
} edu
In addition to satellite-based analyses of TC convection, ground-based lightning detection networks have also been used to identify active TC convection and associate it with TC intensity change. Abarca et al. (2011) indicates that intensifying TCs experience more lightning than nonintensifying TCs, with DeMaria et al. (2012, hereafter D12) proposing the use of TC lightning as a predictor in the operational Statistical Hurricane Intensity Prediction Scheme (SHIPS) rapid intensification index (RII; Kaplan et al. 2015). However, deficiencies exist with current lightning data. For some lightning detection networks based in the United States, detection efficiency can decrease farther away from ground-based detectors (Pessi et al. 2009); therefore, TCs can only be examined if they are within a reasonable range (Abarca et al. 2011). For global lightning networks, such as the World Wide Lightning Location Network (WWLLN), yearly adjustment factors are needed to standardize lightning counts to account for variability due to the addition of more groundbased detectors (D12; Stevenson and Corbosiero 2016), and detection efficiency differs based on TC location (Rudlosky and Shea 2013). Global and satellite-based 
lightning networks also experience a reduction in detection efficiency around local noon (Stevenson et al. 2016, hereafter SCA16; Cecil et al. 2014). Thus, satellites can provide a potential additional source for identifying and characterizing vigorous TC convection, with TOTs better distinguishing active convection when compared with the analyses that only examine cold brightness temperatures (Bedka et al. 2010).

The intent of this study is to examine the distribution of TOTs with respect to current and future TC intensity and other environmental factors. While similar research has been conducted using lightning data as noted above, TOTs can provide an additional (and independent) measure of vigorous TC convection. Therefore, TOTs can serve as a complement to the already-documented distribution of lightning in TCs. Our findings are compared with findings from earlier lightning-based studies, and differences or additional insights are discussed.

\section{Data and methodology}

\section{a. Satellite data}

Two operational geostationary satellites are used to identify TOTs over the North Atlantic TC basin in this study. The first is the Geostationary Operational Environmental Satellite-East (GOES-E), located at $75^{\circ} \mathrm{W}$. The series of GOES-E satellites during the 2004-15 period of analysis provide infrared (IR) imagery at 4-km spatial resolution. The GOES-E conterminous United States (CONUS) sector imagery is used west of $62^{\circ} \mathrm{W}$ and north of $15^{\circ} \mathrm{N}$ with 15 -min temporal resolution, while regions between $50^{\circ}$ and $62^{\circ} \mathrm{W}$ or south of $15^{\circ} \mathrm{N}$ are examined using the GOES-E Northern Hemisphere (NH) scan with 30-min temporal resolution. The second geostationary satellite used to identify TOTs in this analysis is the Meteorological Satellite (Meteosat) Second Generation (MSG), located at $0^{\circ} \mathrm{W}$. MSG offers $3-\mathrm{km}$ spatial and 15-min temporal IR image resolution and is utilized east of $50^{\circ} \mathrm{W}$. While this difference in spatial resolution could impact TOT detection, it should be noted that these spatial resolutions are valid at nadir (viewing zenith angle of $0^{\circ}$ ), with satellite pixel size increasing as satellite viewing zenith angle increases (Minnis 1989). When examining TOTs over a given time period, the quantity of TOTs is expressed as the average number of TOTs per scan over that time period to account for differences in the satellite temporal sampling.

\section{b. Tropical overshooting tops}

The TOTs analyzed in this study are identified using an objective satellite-based detection algorithm (Monette et al. 2012), a derivative of the overshooting top (OT) detection algorithm developed by Bedka et al. (2010). The TOT algorithm begins by first identifying individual candidate TOT pixels that have a 10.7- (GOES-E) or 10.8- $\mu \mathrm{m}$ (MSG) IR brightness temperature (BT) colder than $215 \mathrm{~K}$. Then, the mean BT of the anvil cloud surrounding the TOT candidate pixel is computed using pixels at an $8-\mathrm{km}$ radius in 16 radial directions. At least 9 of 16 anvil pixels must have a BT colder than $225 \mathrm{~K}$, and only these pixels are used to calculate the mean anvil BT. The difference between the minimum TOT BT and the mean anvil BT is termed the brightness temperature difference (BTD).

The final step in identifying a TOT is to calculate the probability that a candidate TOT is an actual TOT. Candidate TOTs are divided into two categories based on their BTDs: those with a BTD less than or equal to $-9 \mathrm{~K}$ and those with a BTD greater than $-9 \mathrm{~K}$, after Monette et al. (2012). TOTs with a BTD greater than $-9 \mathrm{~K}$ are only identified within $100 \mathrm{~km}$ of the TC center, where the coldest cloud tops associated with the central dense overcast are more prevalent (Velden et al. 1998). TOT probability is calculated using a modified Bayesian theorem:

$$
\text { TOT probability }=\frac{\prod_{i=1}^{N} P\left(F \mid C_{\mathrm{TOT}}\right)}{\prod_{i=1}^{N} P\left(F \mid C_{\mathrm{TOT}}\right)+\prod_{i=1}^{N} P\left(F \mid C_{\mathrm{NotTOT}}\right)} .
$$

Here, $P\left(F \mid \boldsymbol{C}_{\mathrm{TOT}}\right)$ and $P\left(F \mid C_{\text {NotTOT }}\right)$ represent the conditional probability of observing a set of properties when a candidate pixel is or is not a TOT, respectively, based on a designated dataset. For candidate GOES-E TOTs, the dataset is 1755 potential TOTs with a BTD between -3 and $-9 \mathrm{~K}$ from 158 GOES-E scans. These potential TOTs have been verified as either a TOT or a non-TOT using 250-m visible Moderate Resolution Imaging Spectroradiometer (MODIS) imagery. Of all the TOTs (non-TOTs) in this dataset, $4.6 \%(4.5 \%)$ have a BTD of $-5.0 \mathrm{~K}$. Therefore, if only BTD is used to calculate the TOT probability, the TOT probability for a candidate TOT with a BTD of $-5.0 \mathrm{~K}$ is $50.5 \%$ [0.046/(0.046 + 0.045)]. All the TOT properties and a description of each property can be seen in Table 1 .

The properties used to calculate TOT probability for candidate TOTs with a BTD less than or equal to $-9 \mathrm{~K}$ differ between the two satellites used in this study and can be seen in Table 2. The conditional probability equations can be found in the supplemental material online. For candidate TOTs identified by GOES, the TOT probability must be greater than or equal to $36 \%$ for a candidate TOT to be identified. This cutoff probability is chosen because it 
TABLE 1. Descriptions of the TOT properties used to calculate the TOT probability.

\begin{tabular}{|c|c|}
\hline TOT property & Description \\
\hline Number of anvil pixels & Number of anvil pixels with a $\mathrm{BT} \leq 225 \mathrm{~K}$ used to calculate the mean anvil BT \\
\hline Number of TOT pixels & $\begin{array}{l}\text { Number of pixels within } 6 \mathrm{~km} \text { of the candidate TOT that are colder than the mean anvil BT plus } \\
\text { half of the BTD (Bedka et al. 2010) }\end{array}$ \\
\hline BTD & Difference between TOT BT and mean anvil BT \\
\hline TOT BT - TT & TOT BT - 12-h National Centers for Environmental Prediction (NCEP) GFS TT \\
\hline Water vapor BT - TOT BT & $6.9-\mu \mathrm{m}$ IR BT - TOT BT (GOES only) \\
\hline Water vapor BT - TOT BT & $6.2-\mu \mathrm{m}$ IR BT - TOT BT (MSG only) \\
\hline 12.0- $\mu \mathrm{m} \mathrm{BT}-$ TOT BT & 12.0- $\mu \mathrm{m}$ IR BT - TOT BT (MSG only) \\
\hline $13.3-\mu \mathrm{m} \mathrm{BT}-$ TOT BT & 13.3- $\mu \mathrm{m} \mathrm{IR} \mathrm{BT} \mathrm{-} \mathrm{TOT} \mathrm{BT}$ \\
\hline Latitude of TC center & $\begin{array}{l}\text { Latitude of the TC center from the NHC best track (see section 2c), interpolated to the satellite } \\
\text { scan time }\end{array}$ \\
\hline
\end{tabular}

has the highest critical success index (CSI) score. The CSI score is the number of TOTs correctly identified divided by the number of TOTs missed or incorrectly identified (Wilks 2006). The CSI is calculated using an independent dataset of 941 potential TOTs. For candidate TOTs identified by MSG, the candidate TOT's probability must be greater than or equal to $49 \%$ to be identified as a TOT. This difference from the GOES probability is probably due to the increased spatial resolution of MSG and additional property. The CSI is calculated using an independent dataset of 310 potential TOTs. Fewer MSG TOTs are used in this analysis as TCs occur more frequently in the GOES-E sector.

The properties used to calculate TOT probability for candidate TOTs with a BTD greater than $-9 \mathrm{~K}$ also differs between the two satellites used in this study and can be seen in Table 2. The equations used to calculate the conditional probabilities can be found in the supplemental material. For candidate TOTs identified by GOES, the TOT probability must be greater than or equal to $78 \%$ for a candidate TOT to be identified. In addition, candidate TOTs need a BTD less than or equal to $-4.5 \mathrm{~K}$ and TOT BT - tropopause temperature (TT) less than or equal to $13 \mathrm{~K}$. This combination of cutoff probability and TOT properties as well as threshold for BTD and TOT BT - TT was chosen as it had the highest CSI based on an independent dataset of 615 potential TOTs. Candidate TOTs identified by MSG need a TOT probability greater than or equal to $71 \%$ to be identified as a TOT, as well as a BTD less than or equal to -4.0 and TOT BT - TT less than or equal to $7 \mathrm{~K}$. Again, these properties and cutoff probability are chosen based on the CSI from an independent dataset of 268 potential TOTs.

The quantity of TOTs will be expressed in two different ways. The first is the TOTs per scan averaged over a chosen time period to account for the differing temporal resolution between satellites. The second is TOT density. TOT density is the number of TOTs per scan normalized to an area of $100 \mathrm{~km}^{2}$. It will be used to compare TOTs within different ranges from the TC center that encompass different area sizes.

\section{c. Period of analysis}

The period of study covers 197 North Atlantic TCs from 2004 to 2015. TC locations and intensities are available every synoptic hour $(0000,0600,1200$, and 1800 UTC) from the National Hurricane Center (NHC) best track (Landsea and Franklin 2013). TOTs are not analyzed when a TC center is within $12 \mathrm{~h}$ of landfall or

TABLE 2. TOT properties used for each TOT probability calculation.

\begin{tabular}{|c|c|c|c|c|}
\hline TOT property & $\begin{array}{c}\text { Used by GOES-E } \\
\text { BTD } \leq-9 \text { K TOT } \\
\text { probability calculation? }\end{array}$ & $\begin{array}{c}\text { Used by MSG } \\
\text { BTD } \leq-9 \text { K TOT } \\
\text { probability calculation? }\end{array}$ & $\begin{array}{c}\text { Used by GOES-E } \\
\text { BTD }>-9 \text { K TOT } \\
\text { probability calculation? }\end{array}$ & $\begin{array}{c}\text { Used by MSG } \\
\text { BTD }>-9 \mathrm{~K} \text { TOT } \\
\text { probability calculation? }\end{array}$ \\
\hline Number of anvil pixels & Yes & Yes & Yes & - \\
\hline Number of TOT pixels & Yes & Yes & Yes & Yes \\
\hline BTD & Yes & Yes & Yes & Yes \\
\hline TOT BT - TT & Yes & Yes & Yes & - \\
\hline Water vapor $\mathrm{BT}-$ TOT $\mathrm{BT}$ & Yes & Yes & - & - \\
\hline $12.0-\mu \mathrm{m} \mathrm{BT}-$ TOT BT & - & Yes & - & Yes \\
\hline $13.3-\mu \mathrm{m} \mathrm{BT}-$ TOT BT & Yes & Yes & Yes & - \\
\hline Latitude of TC center & - & - & Yes & Yes \\
\hline
\end{tabular}




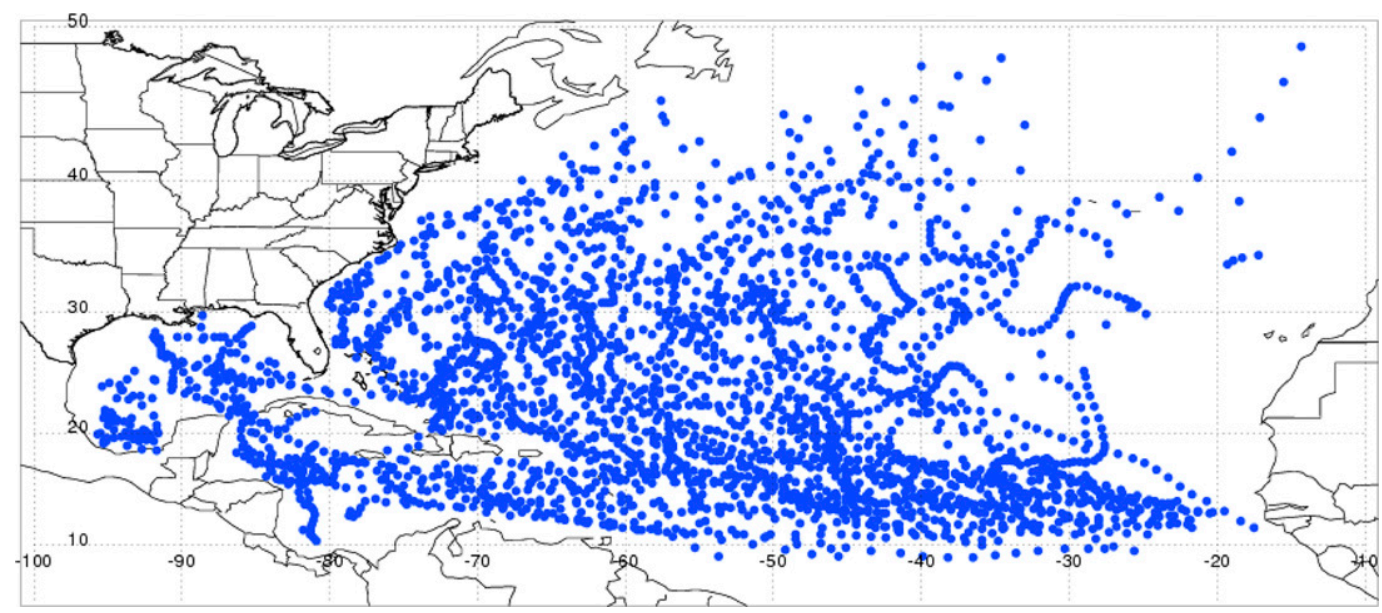

FIG. 1. Location of 2965 synoptic hour locations from 197 Atlantic TCs from 2004 to 2015 used in this analysis.

has reemerged over water in the previous $24 \mathrm{~h}$, which is similar to Kaplan et al. (2010). This is done so the increase in TOTs (Liu and Zipser 2005) and reduction in TC intensity (Kaplan and DeMaria 1995) due to land interactions do not skew this analysis. TOTs are also not analyzed if the TC is classified as subtropical. The location of 2965 synoptic hours used in this analysis can be seen in Fig. 1. Since the TC locations from the best track data are only updated for each synoptic time, the number of TOTs per scan is calculated over the 6-h periods prior to $0000,0600,1200$, and 1800 UTC. To provide a better estimate of TC location for each satellite scan, TC locations and intensities are linearly interpolated to 15-min resolution.

\section{d. Environmental parameters}

To examine associations between TOTs and the TC environment, TOT quantities are compared with two environmental parameters obtained from the SHIPS (DeMaria and Kaplan 1994) output. The first is Reynolds sea surface temperature (RSST; Reynolds and Marsico 1993) at the TC center, estimated in SHIPS from the weekly RSST (D12). The second parameter is deep-layer $(850-200 \mathrm{hPa})$ vertical wind shear diagnosed from the Global Forecast System (GFS) analyses. In SHIPS, the vertical wind shear is averaged within $0-500 \mathrm{~km}$ of the $850-\mathrm{hPa}$ TC center with the TC vortex removed. Since SHIPS is only updated for each synoptic time, the average number of TOTs per scan is calculated over the 6 -h periods prior to $0000,0600,1200$, and 1800 UTC.

\section{Results}

The TOTs from each of the TC cases in the sample are combined to create 12-yr composites. These composites are then examined as a short climatology of TOT behavior in North Atlantic TCs and also to investigate how SST and vertical wind shear can affect the amount, distribution, and evolution of vigorous convection.

\section{a. Diurnal variability}

The diurnal variability in the number of TOTs per scan within $500 \mathrm{~km}$ of the TC center is shown in Fig. 2, plotted as a function of local standard time (LST; local to the TC center). LST is calculated as a decrease in $1 \mathrm{~h}$ from coordinated universal time (UTC) for each $15^{\circ}$ longitude west of the prime meridian and is centered on each $15^{\circ}$ (Glickman 2000). Therefore, the local time between $22.5^{\circ}$ and $7.5^{\circ} \mathrm{W}$ is UTC minus $1 \mathrm{~h}$. TOTs are counted over the hour-long window surrounding each local hour and then divided by the number of satellite scans. The average TOTs per scan are then smoothed over a 3-h period to reduce noise. A semidiurnal cycle with two maxima in TOTs is observed, with one maximum occurring in the predawn around 0400-0500 LST

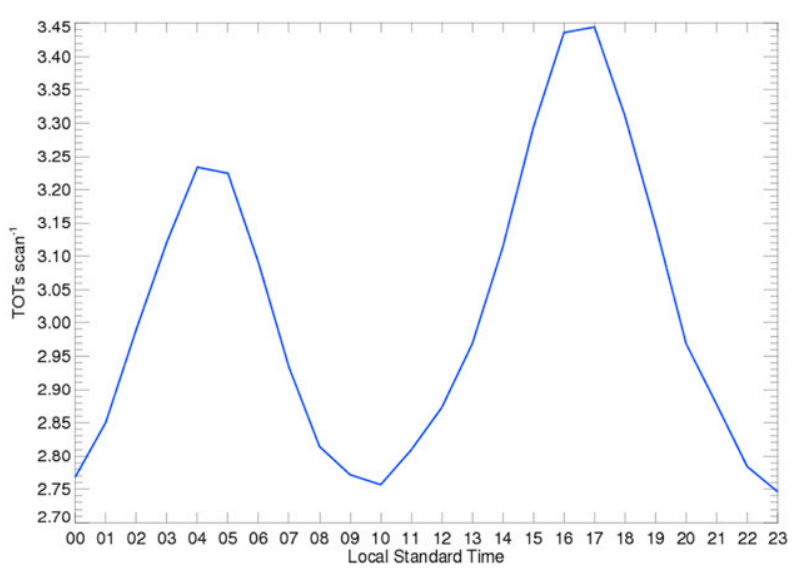

FIG. 2. TOTs per scan within $500 \mathrm{~km}$ of the TC center as a function of LST (local to the TC). 


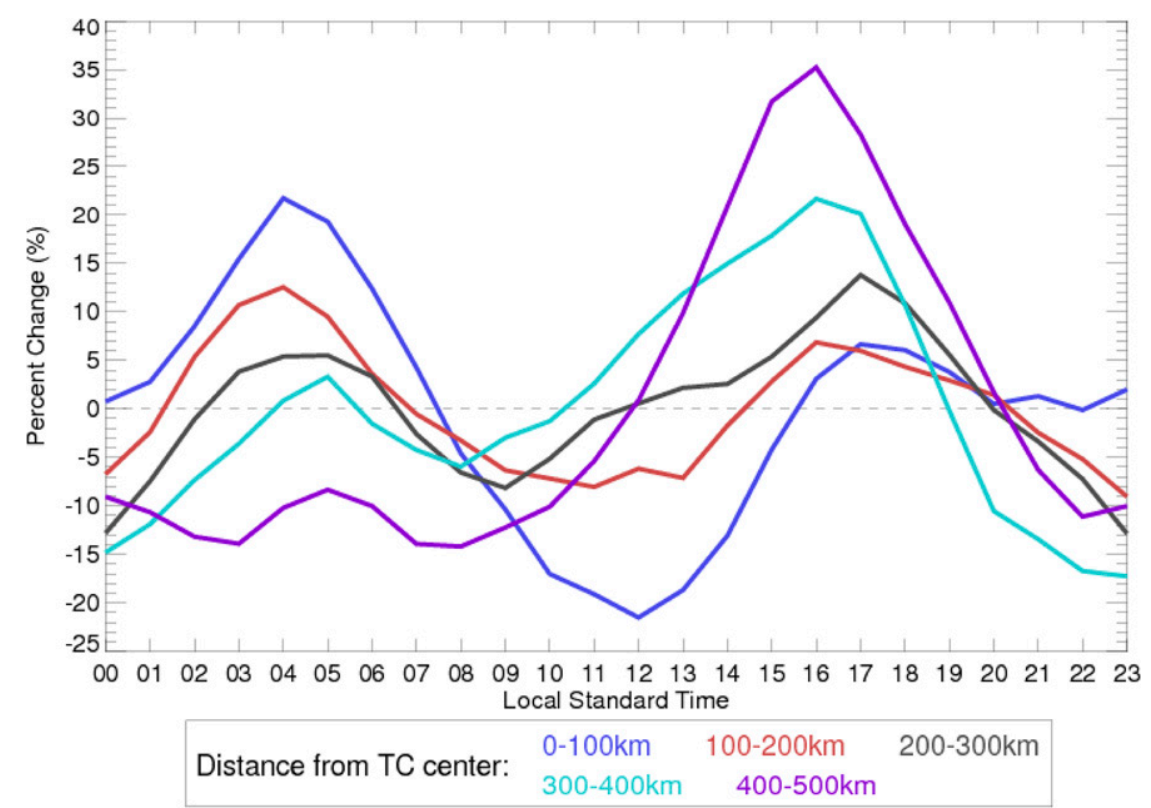

FIG. 3. Percent change from average TOTs per scan within radials from the TC center as a function of LST.

and another in the predusk around 1600-1700 LST. The predawn maximum coincides with the well-documented predawn maximum in tropical convection. For example, Hendon and Woodberry (1993) identified a predusk maximum in deep convective activity using satellite 11- $\mu \mathrm{m}$ BTs. Using Tropical Rainfall Measuring Mission (TRMM) observations, Nesbitt and Zipser (2003) and Liu and Zipser (2005) identified a predawn maximum in precipitation. Specifically for TCs, a maximum in TRMM rain rate within $500 \mathrm{~km}$ of a TC center is observed around 0600 LST (Bowman and Fowler 2015). The timing of the predawn maximum in TOTs per scan does differ from the maxima in lightning within $300 \mathrm{~km}$ of the TC center, which are observed around 0100 LST and from 0900 to 1100 LST (SCA16).

The second maximum in TOTs in the predusk initially appears to be contradictory, as many studies indicate a minimum is observed in tropical oceanic convection during this time (Nesbitt and Zipser 2003; Gray and Jacobson 1977; Liu and Zipser 2005). Bowman and Fowler (2015) identified a semidiurnal harmonic in TC rain rate from TRMM precipitation with a secondary maximum in the afternoon; however, this harmonic only acted to "flatten the afternoon minimum" in rain rate. Land-based convection experiences a diurnal maximum in the late afternoon (Nesbitt and Zipser 2003); however, a semidiurnal cycle is still observed in ocean-based TOTs within $500 \mathrm{~km}$ of the TC center (not shown). One explanation for the second maximum in TOTs in the predusk is the TC diurnal "pulse" observed in GOES 10.7- $\mu \mathrm{m}$ and MSG
10.8- $\mu \mathrm{m}$ IR imagery as documented in Dunion et al. (2014). This pulse in colder BTs begins near the center of a TC around midnight LST and radiates outwards with time.

To investigate this further, Fig. 3 presents the percent change from the average number of TOTs per scan as a function of LST and radial distances from the TC center. Here, the average number of TOTs per scan is defined as the average over all local hours, and percent change is used to account for the different areal extents of each radial. While the two maxima in TOTs per scan are still observed, the location with respect to the TC center differs. For TOTs within $300 \mathrm{~km}$ of the TC center, both maxima are present, in agreement with the semidiurnal signal found in Kossin (2002). A higher percent change in TOTs within $200 \mathrm{~km}$ is observed in the predawn maximum, while TOTs within $300-500 \mathrm{~km}$ of the TC center are more predominant in the predusk maximum. This agrees with the TC diurnal pulse, which reaches $400 \mathrm{~km}$ $(500 \mathrm{~km})$ around 1200 LST (1500 LST), depending on TC size (Dunion et al. 2014). The TC diurnal pulse is also more pronounced for TCs with an intensity greater than $83 \mathrm{kt}\left(1 \mathrm{kt}=0.51 \mathrm{~m} \mathrm{~s}^{-1}\right.$; Dunion et al. 2014). Reducing the TCs in this dataset to only those with an intensity greater than $83 \mathrm{kt}$ results in a percent change of $68 \%$ for TOTs within 400-500 km observed at 1500 LST (not shown) and an increase from a percent change of $35.2 \%$ for TCs of all strengths. TCs with an intensity less than or equal to $83 \mathrm{kt}$ still have a percent change of $29.5 \%$ for TOTs within 400-500 km observed at 1500 LST (not shown). Therefore, 


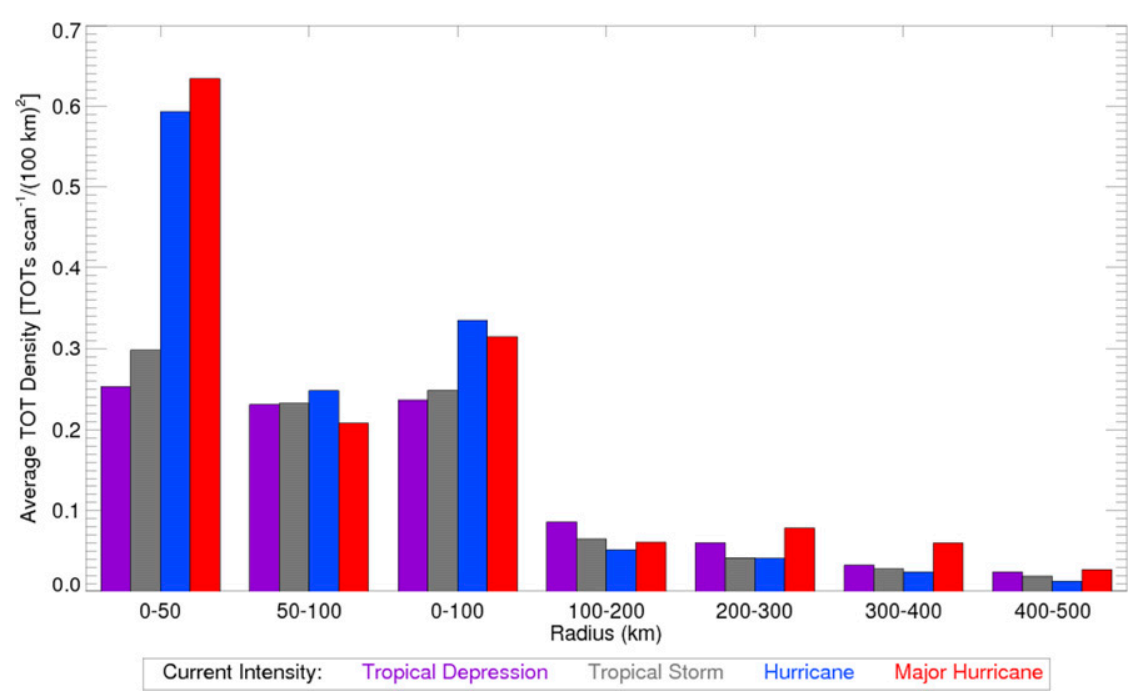

FIG. 4. Average TOT density based on current TC intensity as a function of radius.

it appears the diurnal distribution of TOTs is more dependent on TC structure and dynamics, whereas the lightning distribution could be more associated with the overnight convective maximum related to tropical mesoscale convective systems (Nesbitt and Zipser 2003).

\section{b. Relationship to tropical cyclone intensity and intensity change}

The relationship between the average TOT density and current TC intensity is illustrated in Fig. 4. TCs are partitioned into four different categories based on the NHC best track maximum 1-min sustained surface winds $v$ : tropical depression (TD; $v<34 \mathrm{kt}$ ), tropical storm (TS; $34 \leq v<64 \mathrm{kt}$ ), hurricane (HU; $64 \leq$ $v<96 \mathrm{kt}$ ), and major hurricane (mHU; $v \geq 96 \mathrm{kt}$ ). Within $50 \mathrm{~km}$ of the TC center, hereafter referred to as the eyewall since nearly all eyewall convection is confined to this region (Stern and Nolan 2009), the highest TOT density for all four TC intensity categories is observed. In the eyewall, the highest overall TOT densities are observed for HUs and mHUs. This supports the lightning distribution findings from D12. Between 100 and $200 \mathrm{~km}$, the average TOT density is greater for weaker TCs, and more TOTs are identified in mHUs when compared with other intensities for regions beginning at $200 \mathrm{~km}$ from the TC center and extending outward. This is also consistent with the lightning density distribution from D12. The second-highest TOT density for regions beginning $200 \mathrm{~km}$ from the TC center is observed for TDs, which differs from the lightning density distribution.

Another difference between the distributions of TOT density and lightning density from D12 occurs in the $50-100-\mathrm{km}$ annulus. While the average TOT density is similar for TCs of all strengths, over triple the lightning density is observed in nonhurricane-strength TCs when compared with hurricane-strength TCs (D12). The lightning density from D12 is corroborated by Molinari et al. (1999), who identified a minimum in lightning within $80-100 \mathrm{~km}$ of TC centers, and Jiang et al. (2013), who indicated lightning within approximately $80-160 \mathrm{~km}$ of the TC center is more associated with weaker TCs. Using microwave satellite brightness temperatures, Cecil et al. (2002) indicate the region between roughly 50 and $100 \mathrm{~km}$ from the TC center is characterized by weaker convection, as it exhibits a lower percentage of $85-\mathrm{GHz}$ polarizationcorrected temperature (PCT) colder than $200 \mathrm{~K}$ when compared with other areas around the TC. These warmer 85-GHz PCTs correspond to a lower flash count (Cecil and Zipser 2002) as well as weaker overshooting tops (Liu and Zipser 2005). The discrepancy between these findings and the results presented in Fig. 4 may be partially explained by how TOTs are defined in the TC inner core central dense overcast (CDO) region. While smaller BTD magnitudes are used to identify TOTs among the cold clouds within $100 \mathrm{~km}$ of the TC center, the smaller BT magnitudes could also correspond to the weaker TOTs identified by Liu and Zipser (2005). A greater number of TOTs with a BTD larger than $-9 \mathrm{~K}$ are identified in HU- and mHU-strength TCs (not shown), increasing the TOT density when compared with TDs and TSs.

Average TOT density compared with TC intensity change can be observed in Fig. 5. Subsequent 24-h intensity change $i$ is divided into five categories: rapidly weakening $(i<-20 \mathrm{kt})$, weakening $(-20 \leq i<-5 \mathrm{kt})$, steady $(-5 \leq i \leq 5 \mathrm{kt})$, intensifying $(5<i<30 \mathrm{kt})$, and rapidly intensifying ( $i \geq 30 \mathrm{kt}$ ) (D12; Stevenson and Corbosiero 2016). Overall, TCs that are intensifying and rapidly intensifying exhibit more TOTs than TCs that 


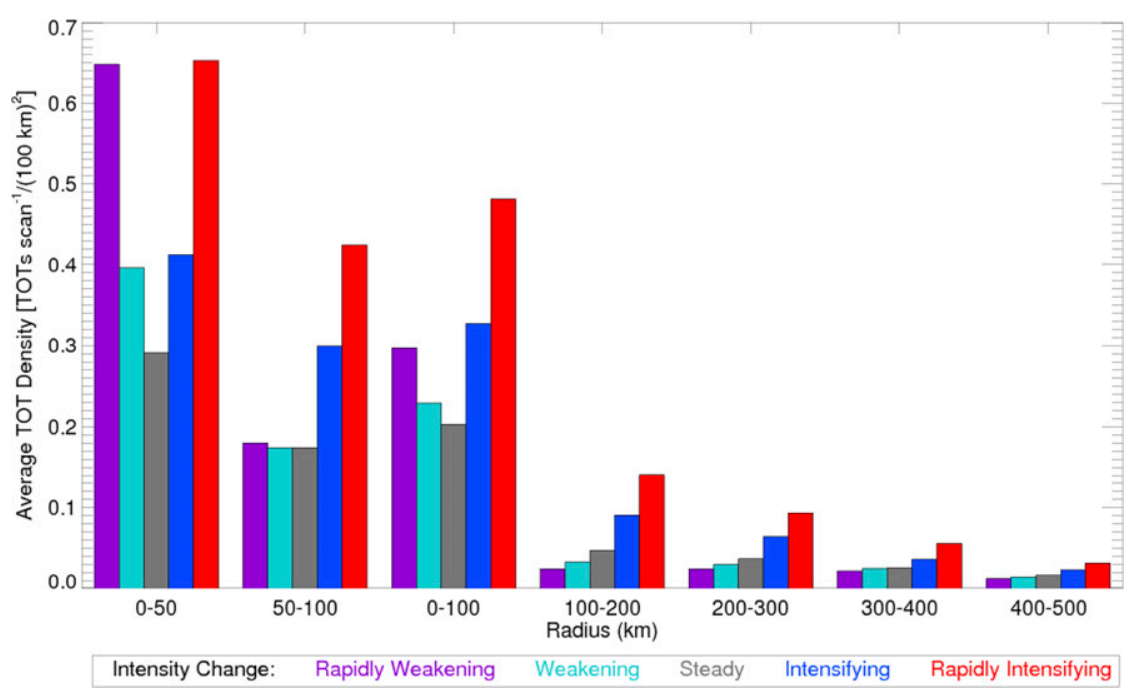

FIG. 5. As in Fig. 4, but based on 24-h TC intensity change.

are either steady state or weakening, especially for radii greater than $50 \mathrm{~km}$. The higher number of TOTs for rapid intensification (RI) cases is in agreement with Monette et al. (2012), who indicated that TOTs within $300 \mathrm{~km}$ of the TC center are skillful at predicting TC RI. These findings complement the D12 lightning study, which reports that lightning within $200-300 \mathrm{~km}$ is higher for TCs that undergo RI. However, the association with inner core lightning, defined as within $100 \mathrm{~km}$ of the TC center, is less certain. D12 indicate greater inner core lightning density is associated with TC rapid weakening (RW) over the following 24h, while Abarca et al. (2011) indicate increased lightning in the inner core is associated with TC intensification in the next $6 \mathrm{~h}$. Our analyses with TOTs indicate that higher densities in the inner core are more suggestive of RI. TOT densities in the eyewall region (within a 50-km radius) are associated with both $\mathrm{RI}$ and RW TC intensity change.

\section{c. Relationship to sea surface temperature}

The relationship between the number of TOTs per scan over 6-h periods compared with the RSST and TC intensity can be observed in the quilt plot in Fig. 6 . The variable $N$ represents the number of 6-h periods for each TC intensity and SST combination. While there is a slight increase in the number of TOTs per scan with increasing TC intensity, a more prominent increase is observed as the number of TOTs per scan exponentially increases with increasing RSST. This increase is especially prominent for SSTs approximately $27^{\circ} \mathrm{C}$ or greater. This is consistent with the study by Graham and Barnett (1987), which indicates oceanic tropical convection increases for SSTs in excess of $27.5^{\circ} \mathrm{C}$, and Heymsfield et al. (2010), where the 13 TC updrafts identified by the ER-2 Doppler radar are associated with SHIPS RSSTs greater than $28^{\circ} \mathrm{C}$. This threshold also exceeds the approximate threshold deemed necessary, but not sufficient, to support deep convection for tropical cyclogenesis identified by Gray (1968). The slight increase in TOTs per scan with increasing TC intensity is potentially a result of the increase in TOTs with SST, as the number of TCs over cooler SSTs decreases with increasing strength, especially for TS and greater intensity.

The increase in the number of TOTs per scan with increasing RSST is similar to the increase in lightning flashes observed over warmer SSTs (SCA16). According to SCA16, high counts of lightning flashes exist for SSTs between $28^{\circ}$ and $30^{\circ} \mathrm{C}$, where the environment supports stronger convection. Unlike SCA16, which saw a decrease in the lightning flash count for SSTs above $30^{\circ} \mathrm{C}$, the number of TOTs per scan continues to increase for SSTs greater than $30^{\circ} \mathrm{C}$ when calculated using TCs of all intensity. The difference between TOTs and lightning is potentially due to the small sample size in SCA16. SCA16 said "Given the low sample size above $30^{\circ} \mathrm{C}$ in our study, it is unclear if the reduction of lightning flash counts at higher SSTs is a robust result." Of the 436 -h periods with a SST exceeding $30^{\circ} \mathrm{C}$ in our dataset, 27 are not included in the SCA16 dataset. Removing these 27 periods from our sample leads to a reduction in the number of TOTs per scan for SSTs exceeding $30^{\circ} \mathrm{C}$, which then becomes analogous to the lightning results from SCA16. Therefore, it appears the reduction in lightning flashes at higher SSTs identified by SCA16 is not a "robust result."

\section{d. Relationship to vertical wind shear}

Figure 7 illustrates the average number of TOTs per scan as a function of TC intensity and vertical 

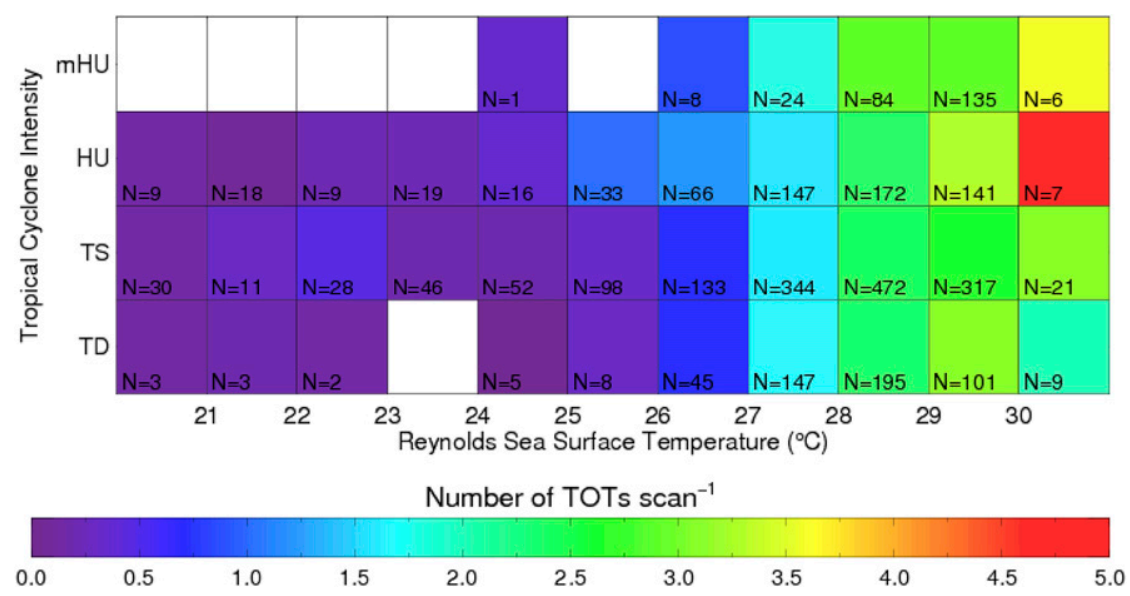

FIG. 6. Number of TOTs per scan as a function of TC intensity and RSST. The variable $N$ represents the number of 6-h time periods for each TC intensity and SST combination.

wind shear. TCs experiencing weak vertical wind shear $\left(<5 \mathrm{~m} \mathrm{~s}^{-1}\right)$ have the highest TOTs per scan, with the number of TOTs per scan decreasing as vertical wind shear increases to moderate $\left(5-10 \mathrm{~m} \mathrm{~s}^{-1}\right)$ and strong $\left(>10 \mathrm{~m} \mathrm{~s}^{-1}\right)$ (Gallina and Velden 2000). This supports the lightning distribution from Abarca et al. (2011). In comparison, D12 indicates inner core lightning increases as shear increases from low to moderate, with a general decrease in lightning for strong shear. Analysis of inner core TOTs (not shown) does indicate a local maximum in the number of TOTs per scan around $5 \mathrm{~m} \mathrm{~s}^{-1}$ of vertical wind shear; however, this maximum is lower than the number of TOTs per scan for vertical wind shear less than $2 \mathrm{~m} \mathrm{~s}^{-1}$.

\section{e. Relationship to TC motion}

Figure 8 illustrates the average number of TOTs per scan as a function of TC intensity and TC motion. TC motion has a smaller impact on the number of TOTs per scan when compared with vertical wind shear. TC motion is calculated for every 6 -h best track position using a 12-h centering scheme similar to Corbosiero and Molinari (2003). The relationship between the number of TOTs per scan for slow $\left(<3 \mathrm{~m} \mathrm{~s}^{-1}\right)$, medium (3$\left.6 \mathrm{~m} \mathrm{~s}^{-1}\right)$, and fast $\left(>6 \mathrm{~m} \mathrm{~s}^{-1}\right)$ moving TCs is weaker than that for the different categories of vertical wind shear. Even though slow-motion mHUs have the largest number of TOTs per scan, slow-motion TCs have the lowest number of TOTs per scan when totaled over all intensities. This is due to the average intensity of slowmotion TCs, which is about $9 \mathrm{~m} \mathrm{~s}^{-1}$ weaker than mediumor fast-moving TCs. Weaker TCs generally experience fewer TOTs, based on the results in Fig. 4. Disregarding TC intensity, medium-motion TCs have the highest number of TOTs per scan, with TOTs decreasing slightly for TCs with a fast motion. While the reasoning for the decrease in TOTs as TC motion increases from medium to fast is unclear, it corroborates with the decrease in lightning observed by Corbosiero and Molinari (2003) as the TC motion increased.

\section{f. Azimuthal distribution}

Vertical wind shear and TC motion can affect the azimuthal distribution of TC convection, identified in lightning by Corbosiero and Molinari $(2002,2003)$. To corroborate this distribution of TC convection, the location of TOTs with respect to the direction of shear or motion are analyzed with icosagons [based on Abarca et al. (2011)]. Icosagons are created by transforming the TOT locations from geographical coordinates into a radius and azimuthal angle from the TC center. TOTs are summed into 20 azimuthal bins ( $18^{\circ}$ spacing) with respect to the azimuthal angle from the shear/motion direction and as a function of shear/motion magnitude. Then, TOTs

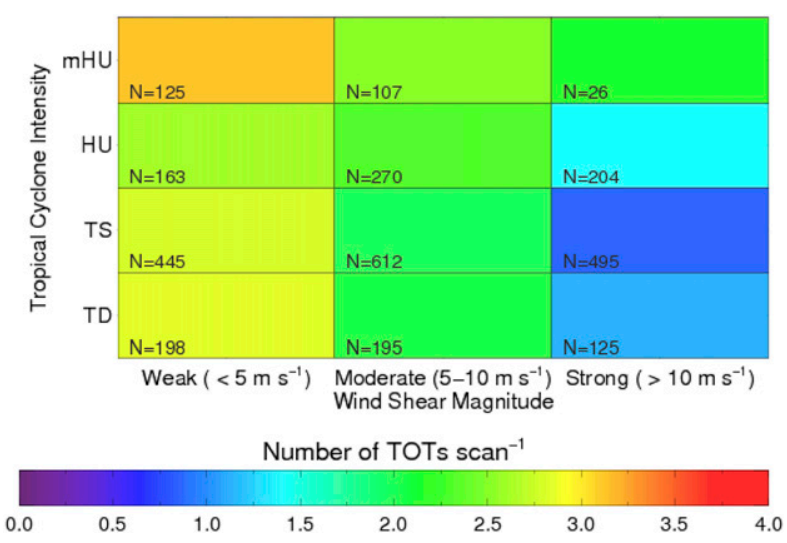

FIG. 7. As in Fig. 6, but as a function of TC intensity and 850-200-hPa vertical wind shear. 

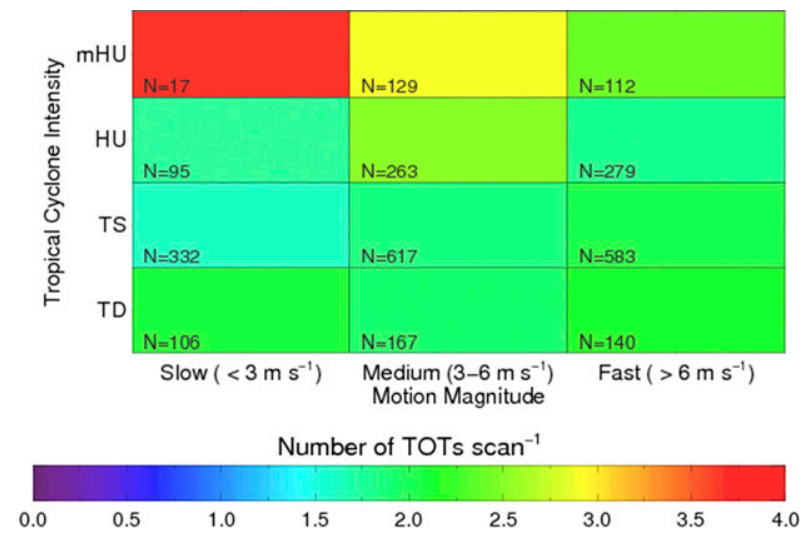

FIG. 8. As in Fig. 6, but as a function of TC intensity and TC motion.

are averaged by the number of satellite scans for each shear/motion magnitude category. The point of each vertex is plotted in a framework representing the number of TOTs per scan observed in each azimuthal bin. Vertices are then connected, and the shape of the icosagon shows the preferred azimuthal location of TOTs with respect to the shear/motion direction.

The icosagons based on the magnitude of the shear are shown in Fig. 9. Range rings for each quartile between 0 and the maximum number of TOTs per scan are plotted for reference. TCs are divided into left and right quadrants, with quadrants in (opposite) the direction of the shear vector considered downshear (upshear). The numbers in each quadrant indicate the percent of TOTs observed in each quadrant for each shear category. For all vertical wind shear categories, TOTs are more predominant downshear, supporting the lightning distribution from Corbosiero and Molinari (2002). In addition, the TOT asymmetry increases as the magnitude of the vertical wind shear increases. For all TOTs within $300 \mathrm{~km}$ of the TC center (not shown), the percent of TOTs that are downshear increases from $57.1 \%$ to $74.1 \%$ for weak shear and strong shear, respectively. In the inner core (Fig. 9, left), downshear left (DSL) is the more preferred quadrant for TOTs as vertical wind shear increases, supporting the lightning distribution from SCA16. SCA16 explain that vertical wind shear tilts the TC vortex downshear (Jones 1995), resulting in an increase in the vertical motions downshear in attempts to realign the vortex (Reasor et al. 2004). Downshear right (DSR) is the TOT's preferred quadrant for the outer rainbands (Fig. 9, right) as the shear increases. This also supports SCA16, which indicates this quadrant is preferred because of adiabatic processes.

The azimuthal distribution of TOTs with respect to the direction of TC motion can be seen in Fig. 10. Quadrants in (opposite) the direction of the motion vector are considered front (rear). In the inner core (Fig. 10, left), TC motion has little impact on the azimuthal distribution of TOTs, upholding the lightning distribution from SCA16. In the outer rainbands (Fig. 10, right), front and right of motion is the preferred
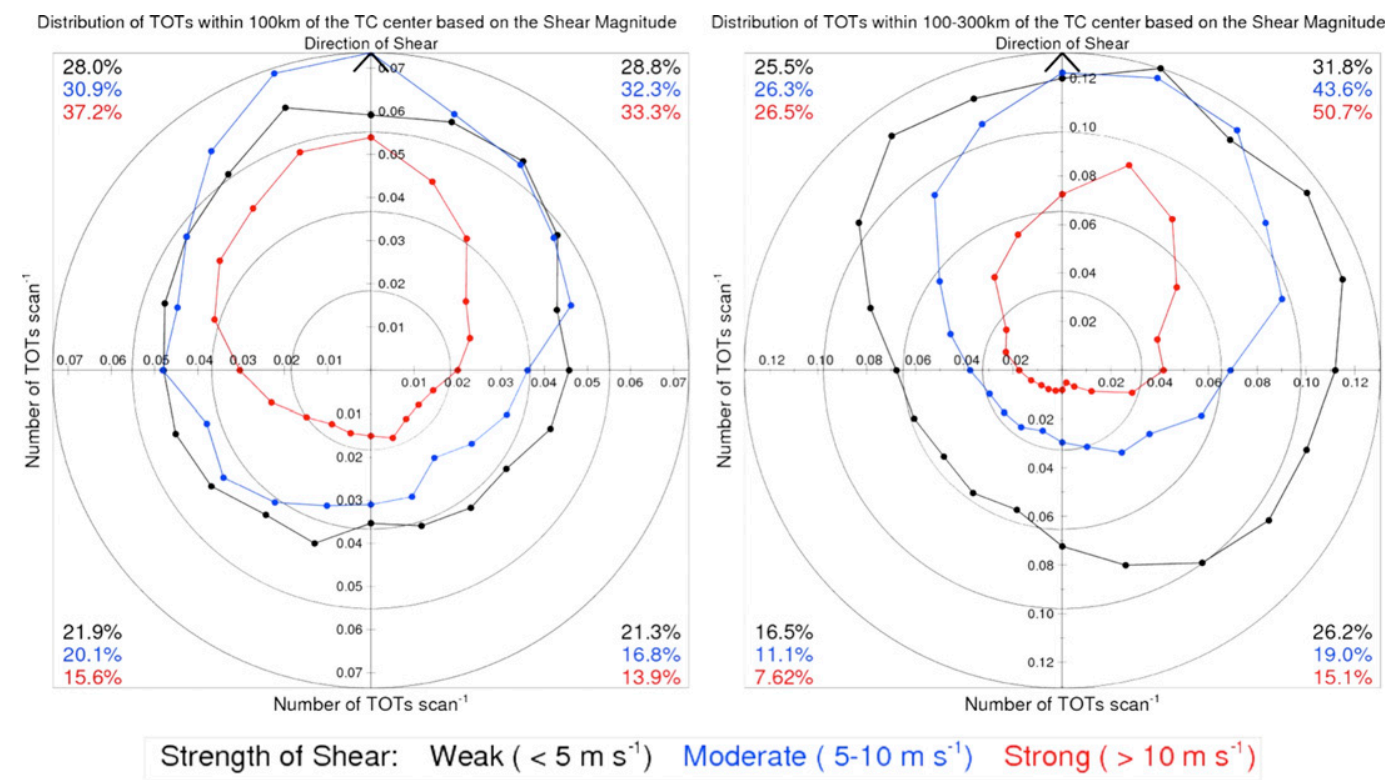

FIG. 9. Icosagons indicating the azimuthal distribution of TOTs with respect to the direction of the vertical wind shear for (left) 0-100 and (right) 100-300 km of the TC center. Percentages represent the percent of TOTs in each given quadrant based on the shear category. Range rings for each quartile between 0 and the maximum number of TOTs per scan are plotted for reference. 


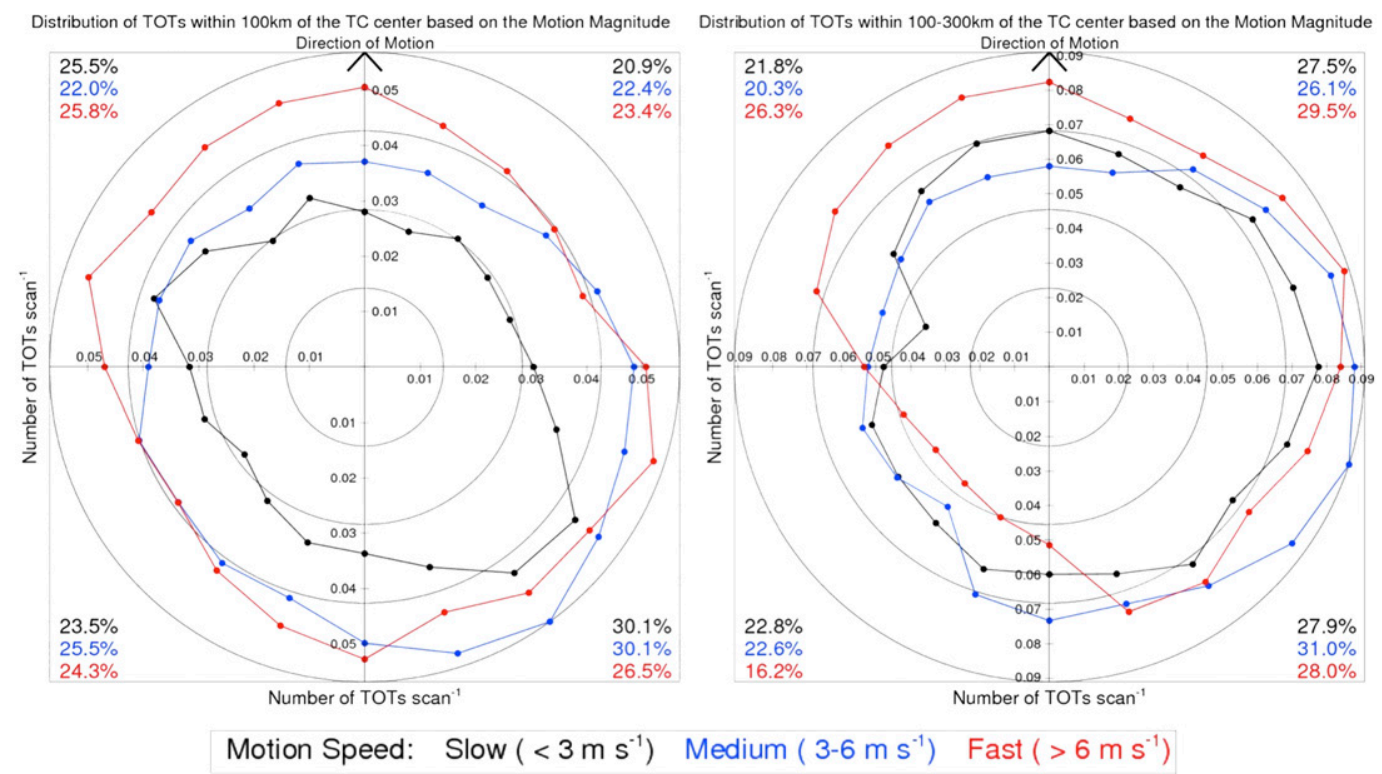

FIG. 10. As in Fig. 9, but with respect to the direction of the TC motion.

location for TOTs, with maxima broadly distributed to the right of the motion vector. For slow TCs with no vertical shear, upward vertical motion is favored in the right front quadrant (Frank and Ritchie 1999), consistent with the TOT and lightning distribution (SCA16). Convection is favored in the right front quadrant because of frictional convergence (Shapiro 1983); however, studies have also noted a maximum in rain rate in the right rear quadrant of TCs (Frank 1977). The TOTs' preferred location of right and front of TC motion may also be impacted by vertical wind shear. The median direction of vertical wind shear with respect to TC motion is opposite and to the right of TC motion (right rear quadrant or southeast if motion is directed due north). Downshear and DSL of the vertical wind shear is then the right rear and right front quadrant of TCs with respect to TC motion.

The distribution of TOTs as a function of the subsequent 24-h TC intensity change based on vertical wind shear direction can be observed in Fig. 11. Overall, the preferred quadrant for TOTs, regardless of intensity change, is DSL in the inner core of the TC and DSR within $100-300 \mathrm{~km}$ of the TC center. However, TOTs are more distributed as the 24-h intensity change increases. The greatest percentage of TOTs occurring downshear of the vertical wind direction $(65.5 \%)$ occurs for TCs that are weakening, while the lowest percentage $(61.3 \%)$ occurs for TCs beginning RI. The increase in symmetry is slightly correlated to the decrease in vertical wind shear, as RW TCs in this dataset experience an average of $9.2 \mathrm{~m} \mathrm{~s}^{-1}$ of vertical wind shear, while RI TCs experience only $5.3 \mathrm{~m} \mathrm{~s}^{-1}$ of vertical wind shear. The reduction of vertical wind shear and increase in TOT symmetry for RI cases agrees with Kaplan et al. (2010). Thus, TOT symmetry, as well as frequency, increases as the subsequent 24-h TC intensity change increases. An exception occurs as TC intensity change increases from $i<-20 \mathrm{kt}(\mathrm{RW})$ to $-20 \leq i<-5 \mathrm{kt}$ (weakening) because of the large number of TOTs within the inner core for RW TCs.

Further analysis of the distribution of TOTs for rapidly intensifying TCs with respect to the direction of the vertical wind shear can be seen in Fig. 12. Each range ring represents $50 \mathrm{~km}$, with each box indicating the number of TOTs within an area of approximately $12 \mathrm{~km}^{2}$. While more TOTs are observed in the DSR quadrant overall, TOTs within $100 \mathrm{~km}$ of the TC center appear to have a preference for the DSL quadrant, consistent with Fig. 11. This preference for the DSL quadrant from 51 RI TCs confirms the lightning observed in Hurricane Edouard (2014; Zawislak et al. 2016) and is potentially due to increased upward motion in this quadrant (Rogers et al. 2016). The resulting preference for TOTs in the DSR quadrant within $100-300 \mathrm{~km}$ of the TC center also agrees with the lightning distribution observed in Hurricane Earl (2010; Stevenson et al. 2014).

\section{Conclusions}

This study investigates the climatology of deep convection in North Atlantic tropical cyclones (TCs) using a satellite-based tropical overshooting tops (TOTs) detection algorithm. This is accomplished by analyzing the 

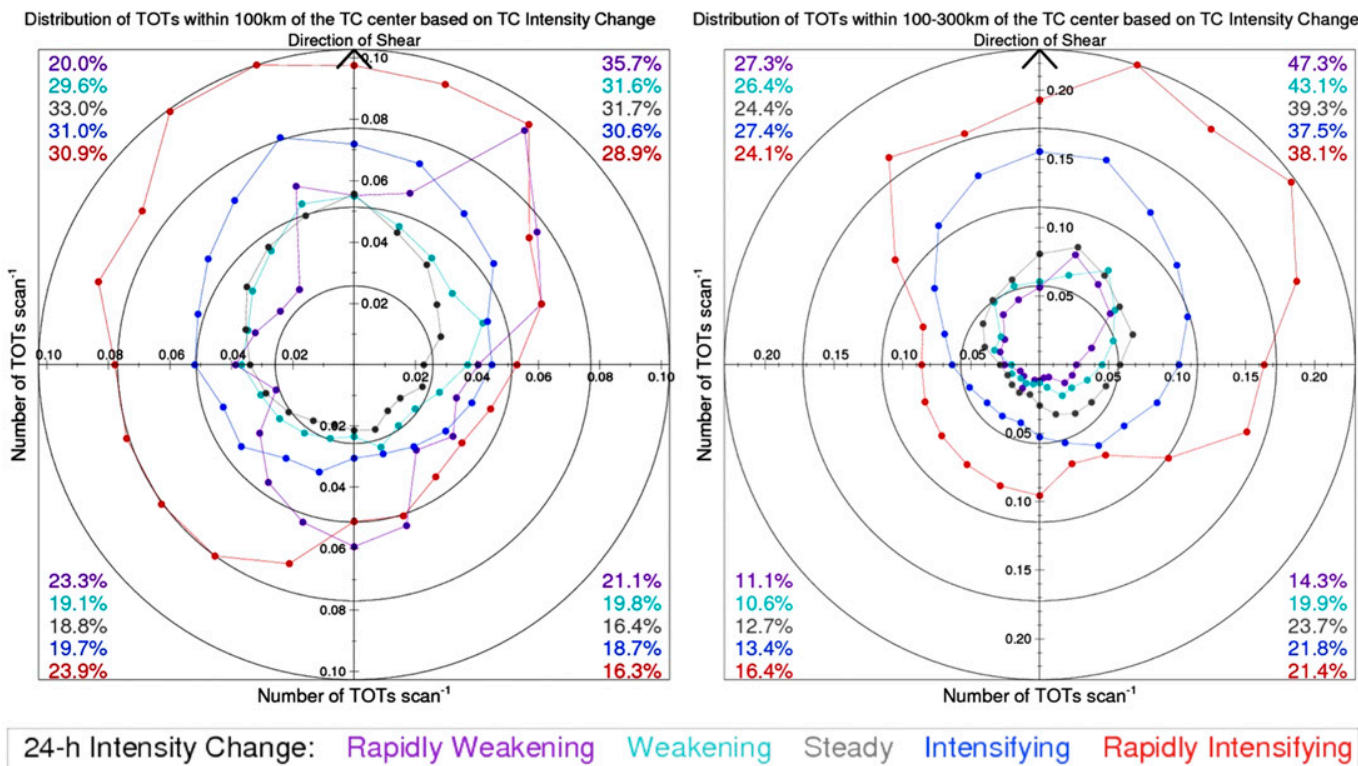

24-h Intensity Change: Rapidly Weakening Weakening Steady Intensifying Rapidly Intensifying

FIG. 11. As in Fig. 9, but for TC intensity change with respect to the direction of the vertical wind shear.

number and distribution of TOTs for 197 Atlantic TCs from 2004 to 2015. While previous studies have examined the distribution of TC convection, mainly through the use of lightning data, TOTs can provide an additional source to identify active TC convection for comparison with the lightning-based studies. The TOT analyses also offer additional insights into TC convective behavior that are less apparent via lightning data.

TOTs within $500 \mathrm{~km}$ of the TC center exhibit distinct diurnal variations. Two maxima are observed around predawn and predusk local to the TC. The first maximum is well documented and also coincides with a maximum in lightning (SCA16). These TOTs preferentially occur within $300 \mathrm{~km}$ of the TC center. TOTs from the second maximum occur in the outer regions of the TC and could be associated with the TC diurnal pulse (Dunion et al. 2014). This maximum is not documented in previous lightning studies; however, those studies concentrated on the inner $300 \mathrm{~km}$ of the TC, whereas the TOTs associated with this predusk maximum are preferentially observed within $200-500 \mathrm{~km}$ of the TC center.

The density and distribution of TOTs can also be influenced by the TC intensity and 24-h intensity change. In the eyewall region (within $50 \mathrm{~km}$ from the TC center), TOTs are more commonly found in hurricane (HU)- and major hurricane (mHU)-strength TCs, complementing the lightning research (D12). Between 50 and $100 \mathrm{~km}$ of the TC center, a similar number of TOTs are observed for TCs regardless of intensity. This is in contrast to lightning, which has a much stronger signature in this annulus for weaker TCs (D12). In outer radials, tropical depression
(TD)- and mHU-strength TCs experience the most TOTs. This is also in contrast to lightning data, where TDs experience the fewest lightning strikes in this region. Therefore, the density of TOTs and lightning together can help identify the evolving structure of the TC, as weaker and more unorganized TCs will tend to have a greater TOT density but a lesser lightning density. TCs that are intensifying or rapidly intensifying (RI) experience a greater TOT density. An exception occurs within the eyewall region, where high TOT numbers can be associated with both RI and rapidly weakening (RW) TCs.

The TOTs can further be used to identify the relationship between TC convection and environmental influences. An exponential relationship exists between the number of TOTs per scan and increasing SST, even at higher $\left(>30^{\circ} \mathrm{C}\right)$ SST values. While this finding differs from previous lightning research, SCA16 questioned "if the reduction of lightning flash counts at higher SSTs is a robust result." Vertical wind shear over the TC was also examined, and not unexpectedly, it was found that increasing the vertical wind shear magnitude acts to decrease the number of TOTs per scan. TC motion also can affect the number of TOTs per scan; however, it has a smaller impact when compared with the vertical wind shear. These two results generally corroborate the lightning results from Abarca et al. (2011) and Corbosiero and Molinari (2003).

The distribution of TOTs with respect to the direction of the vertical wind shear and TC motion are in general agreement with the distribution of lightning. TC motion has little impact on the azimuthal distribution of TOTs, 


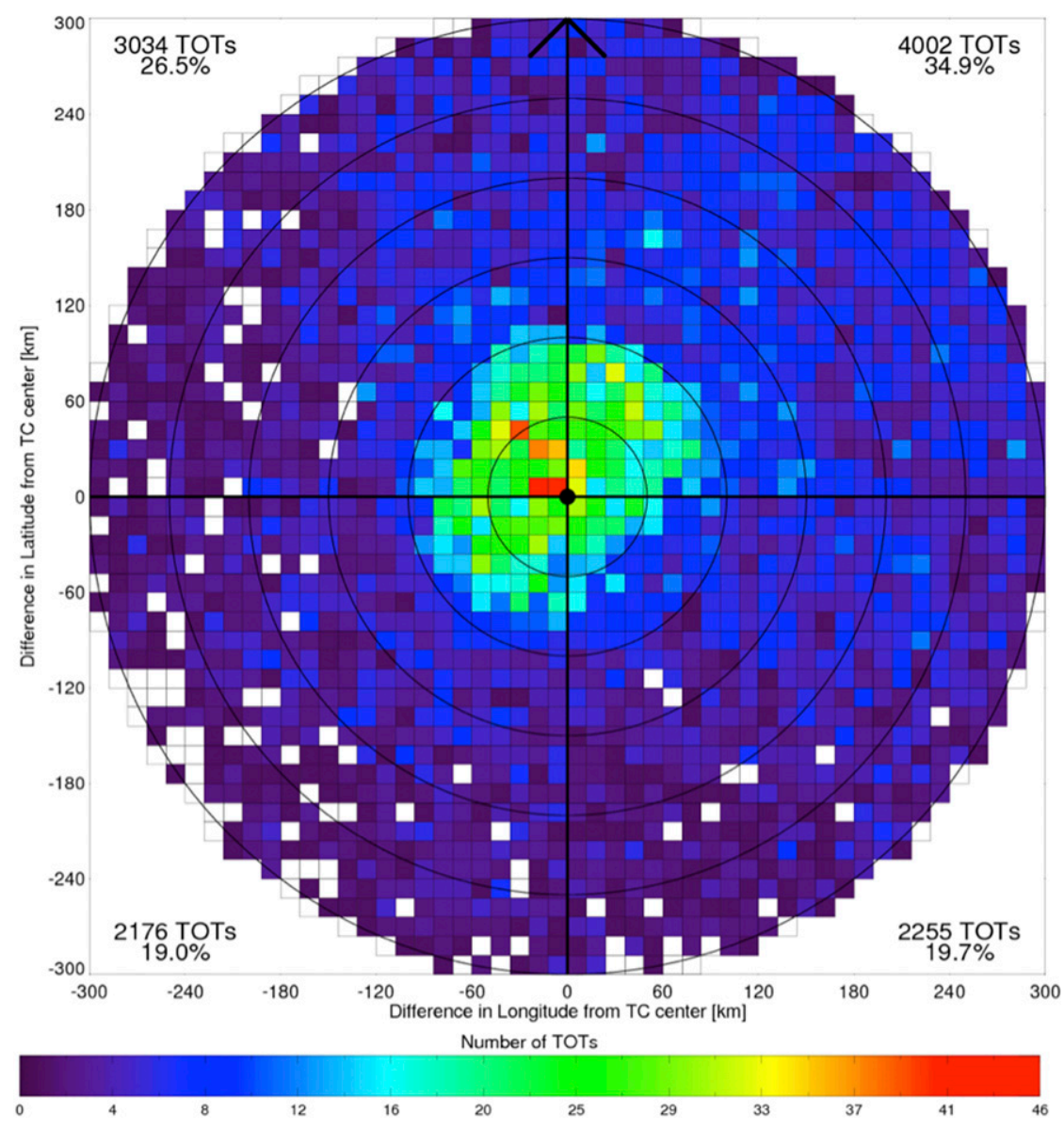

FIG. 12. Distribution of TOTs within $300 \mathrm{~km}$ of the TC center with respect to the direction of the vertical wind shear for RI TCs. Each range ring represents $50 \mathrm{~km}$, with each box indicating the number of TOTs within an area of approximately $12 \mathrm{~km}^{2}$ for all RI cases.

with a slight preference for higher densities right of motion. TOTs are more predominant downshear, with the TOT asymmetry increasing as the magnitude of the vertical wind shear increases. Within $100 \mathrm{~km}$ of the TC center, downshear left (DSL) is the more preferred quadrant for TOTs as vertical wind shear increases, and downshear right (DSR) is the preferred quadrant for TOTs between 100 and $300 \mathrm{~km}$ of the TC center. As $24-\mathrm{h}$ TC intensity change increases, TOTs are more symmetrically distributed with respect to the shear direction. Specifically for RI TCs, more TOTs are observed in the DSR quadrant within $300 \mathrm{~km}$ of the TC center. TOTs within $100 \mathrm{~km}$ of the TC center have a preference for the DSL quadrant, which supports the lightning observed in Hurricane Edouard (2014; Zawislak et al.2016). The resulting preference for the DSR quadrant for TOTs within $100-300 \mathrm{~km}$ of the TC center supports the lightning distribution observed in Hurricane Earl (2010; Stevenson et al. 2014).

In summary, this study documents a short climatology of TOTs in North Atlantic TCs and highlights the similarities and differences between recent lightning research studies. Some new insights are offered, such as the reduction in lightning with SST observed by SCA16 potentially due to the dataset, with the potential for this tool to be applied in other TC basins. Future work will include examining individual TCs to provide a more detailed comparison between the behavior of TOTs and lightning. For example, TCs of the same intensity or undergoing the same intensity change can be clustered and studied to identify factors that lead to similar, or differing, TOT and lightning densities and ultimately to provide additional insights into TC behavior.

Acknowledgments. The author gratefully thanks Chris Velden for his help revising this paper as well as Jason Dunion and two anonymous reviewers for their contributions to this manuscript. This project was funded by the GOES-R Risk Reduction Program via NOAA Cooperative Agreement NA15NES4320001. 


\section{REFERENCES}

Abarca, S. F., K. L. Corbosiero, and D. Vollaro, 2011: The World Wide Lightning Location Network and convective activity in tropical cyclones. Mon. Wea. Rev., 139, 175-191, doi:10.1175/ 2010MWR3383.1.

Bedka, K. M., J. Brunner, R. Dworak, W. Feltz, J. Otkin, and T. Greenwald, 2010: Objective satellite-based overshooting top detection using infrared window channel brightness temperature gradients. J. Appl. Meteor. Climatol., 49, 181-202, doi:10.1175/2009JAMC2286.1.

Bowman, K. P., and M. D. Fowler, 2015: The diurnal cycle of precipitation in tropical cyclones. J. Climate, 28, 5325-5334, doi:10.1175/JCLI-D-14-00804.1.

Cecil, D. J., and E. J. Zipser, 2002: Reflectivity, ice scattering, and lightning characteristics of hurricane eyewalls and rainbands. Part II: Intercomparison of observations. Mon. Wea. Rev., 130, 785-801, doi:10.1175/1520-0493(2002)130<0785:RISALC >2.0.CO;2.

- — - and S. W. Nesbitt, 2002: Reflectivity, ice scattering, and lightning characteristics of hurricane eyewalls and rainbands. Part I: Quantitative description. Mon. Wea. Rev., 130, 769-784, doi:10.1175/1520-0493(2002)130<0769:RISALC $>2.0 . C O ; 2$.

_ D. E. Buechler, and R. J. Blakeslee, 2014: Gridded lightning climatology from TRMM-LIS and OTD: Dataset description. Atmos. Res., 135-136, 404-414, doi:10.1016/j.atmosres.2012.06.028.

Corbosiero, K. L., and J. Molinari, 2002: The effects of vertical wind shear on the distribution of convection in tropical cyclones. Mon. Wea. Rev., 130, 2110-2123, doi:10.1175/ 1520-0493(2002)130<2110:TEOVWS > 2.0.CO;2.

- and -2003 : The relationship between storm motion, vertical wind shear, and convective asymmetries in tropical cyclones. J. Atmos. Sci., 60, 366-376, doi:10.1175/1520-0469(2003)060<0366: TRBSMV $>2.0 . \mathrm{CO} ; 2$

DeMaria, M., and J. Kaplan, 1994: A Statistical Hurricane Intensity Prediction Scheme (SHIPS) for the Atlantic basin. Wea. Forecasting, 9, 209-220, doi:10.1175/1520-0434(1994)009<0209: ASHIPS $>2.0 . \mathrm{CO} ; 2$.

_ - T. T. DeMaria, J. A. Knaff, and D. Molenar, 2012: Tropical cyclone lightning and rapid intensity change. Mon. Wea. Rev., 140, 1828-1842, doi:10.1175/MWR-D-11-00236.1.

Dunion, J. P., C. D. Thorncroft, and C. S. Velden, 2014: The tropical cyclone diurnal cycle of mature hurricanes. Mon. Wea. Rev., 142, 3900-3919, doi:10.1175/MWR-D-13-00191.1.

Dvorak, V. F., 1975: Tropical cyclone intensity analysis and forecasting from satellite imagery. Mon. Wea. Rev., 103, 420-430, doi:10.1175/1520-0493(1975)103<0420:TCIAAF $>2.0$. CO;2.

Frank, W. M., 1977: The structure and energetics of the tropical cyclone: I. Storm structure. Mon. Wea. Rev., 105, 1119-1135, doi:10.1175/1520-0493(1977)105<1119:TSAEOT>2.0.CO;2.

—_, and E. A. Ritchie, 1999: Effects of environmental flow upon tropical cyclone structure. Mon. Wea. Rev., 127, 2044-2061, doi:10.1175/1520-0493(1999)127<2044:EOEFUT>2.0.CO;2.

Gallina, G. M., and C. S. Velden, 2000: A quantitative look at the relationship between environmental vertical wind shear and tropical cyclone intensity change utilizing enhanced satellite wind information. 24th Conf. on Hurricanes and Tropical Meteorology, Fort Lauderdale, FL, Amer. Meteor. Soc., 256-257.

Glickman, T., Ed., 2000: Glossary of Meteorology. 2nd ed. Amer. Meteor. Soc., 855 pp. [Available online at http://glossary. ametsoc.org/.]

Graham, N., and T. P. Barnett, 1987: Sea surface temperature, surface wind divergence, and convection over tropical oceans. Science, 238, 657-659, doi:10.1126/science.238.4827.657.
Gray, W. M., 1968: Global view of the origin of tropical disturbances and storms. Mon. Wea. Rev., 96, 669-700, doi:10.1175/ 1520-0493(1968)096<0669:GVOTOO>2.0.CO;2.

_ and R. W. Jacobson, 1977: Diurnal variation of deep cumulus convection. Mon. Wea. Rev., 105, 1171-1188, doi:10.1175/ 1520-0493(1977)105<1171:DVODCC > 2.0.CO;2.

Hendon, H. H., and K. Woodberry, 1993: The diurnal cycle of tropical convection. J. Geophys. Res., 98, 16 623-16637, doi:10.1029/ 93JD00525.

Heymsfield, G. M., L. Tian, A. J. Heymsfield, L. Li, and S. Guimond, 2010: Characteristics of deep tropical and subtropical convection from nadir-viewing high-altitude airborne Doppler radar. J. Atmos. Sci., 67, 285-308, doi:10.1175/2009JAS3132.1.

Jiang, H., E. M. Ramirez, and D. J. Cecil, 2013: Convective and rainfall properties of tropical cyclone inner cores and rainbands from 11 years of TRMM data. Mon. Wea. Rev., 141, 431-450, doi:10.1175/MWR-D-11-00360.1.

Jones, S. C., 1995: The evolution of vortices in vertical shear. I: Initially barotropic vortices. Quart. J. Roy. Meteor. Soc., 121, 821-851, doi:10.1002/qj.49712152406.

Kaplan, J., and M. DeMaria, 1995: A simple empirical model for predicting the decay of tropical cyclone winds after landfall. J. Appl. Meteor., 34, 2499-2512, doi:10.1175/ 1520-0450(1995)034<2499:ASEMFP > 2.0.CO;2.

_ _ _ , and J. A. Knaff, 2010: A revised tropical cyclone rapid intensification index for the Atlantic and eastern North Pacific basins. Wea. Forecasting, 25, 220-241, doi:10.1175/ 2009WAF2222280.1.

— on tropical cyclone rapid intensification predictability utilizing statistical models. Wea. Forecasting, 30, 1374-1396, doi:10.1175/WAF-D-15-0032.1.

Kossin, J. P., 2002: Daily hurricane variability inferred from GOES infrared imagery. Mon. Wea. Rev., 130, 2260-2270, doi:10.1175/1520-0493(2002)130<2260:DHVIFG >2.0.CO;2.

Landsea, C. W., and J. L. Franklin, 2013: Atlantic hurricane database uncertainty and presentation of a new database format. Mon. Wea. Rev., 141, 3576-3592, doi:10.1175/MWR-D-12-00254.1.

Liu, C., and E. J. Zipser, 2005: Global distribution of convection penetrating the tropical tropopause. J. Geophys. Res., 110, D23104, doi:10.1029/2005JD006063.

Minnis, P., 1989: Viewing zenith angle dependence of cloudiness determined from coincident GOES East and GOES West data. J. Geophys. Res., 94, 2303-2320, doi:10.1029/JD094iD02p02303.

Molinari, J., P. Moore, and V. Idone, 1999: Convective structure of hurricanes as revealed by lightning locations. Mon. Wea. Rev., 127, 520-534, doi:10.1175/1520-0493(1999)127<0520: CSOHAR $>2.0 . \mathrm{CO} ; 2$.

Monette, S. A., C. S. Velden, K. S. Griffin, and C. M. Rozoff, 2012: Examining trends in satellite-detected tropical overshooting tops as a potential predictor of tropical cyclone rapid intensification. J. Appl. Meteor. Climatol., 51, 1917-1930, doi:10.1175/JAMC-D-11-0230.1.

Nesbitt, S. W., and E. J. Zipser, 2003: The diurnal cycle of rainfall and convective intensity according to three years of TRMM measurements. J. Climate, 16, 1456-1475, doi:10.1175/ 1520-0442-16.10.1456.

Olander, T. L., and C. S. Velden, 2009: Tropical cyclone convection and intensity analysis using differenced infrared and water vapor imagery. Wea. Forecasting, 24, 1558-1572, doi:10.1175/ 2009WAF2222284.1.

Pessi, A., S. Businger, K. L. Cummins, N. W. S. Demetriades, M. Murphy, and B. Pifer, 2009: Development of a long-range 
lightning detection network for the Pacific: Construction, calibration, and performance. J. Atmos. Oceanic Technol., 26, 145-166, doi:10.1175/2008JTECHA1132.1.

Reasor, P. D., M. T. Montgomery, and L. D. Grasso, 2004: A new look at the problem of tropical cyclones in vertical shear flow: Vortex resiliency. J. Atmos. Sci., 61, 3-22, doi:10.1175/ 1520-0469(2004)061<0003:ANLATP > 2.0.CO;2.

Reynolds, R. W., and D. C. Marsico, 1993: An improved real-time global sea surface temperature analysis. J. Climate, 6, 114-119, doi:10.1175/1520-0442(1993)006<0114:AIRTGS>2.0.CO;2.

Rogers, R. F., J. A. Zhang, J. Zawislak, H. Jiang, G. R. Alvey III, E. J. Zipser, and S. N. Stevenson, 2016: Observations of the structure and evolution of Hurricane Edouard (2014) during intensity change. Part II: Kinematic structure and the distribution of deep convection. Mon. Wea. Rev., 144, 3355-3376, doi:10.1175/MWR-D-16-0017.1.

Rudlosky, S. D., and D. T. Shea, 2013: Evaluation WWLLN performance relative to TRMM/LIS. Geophys. Res. Lett., 40, 2344-2348, doi:10.1002/grl.50428.

Shapiro, L. J., 1983: Asymmetric boundary layer flow under a translating hurricane. J. Atmos. Sci., 40, 1984-1998, doi:10.1175/ 1520-0469(1983)040<1984:TABLFU > 2.0.CO;2.

Steranka, J., E. B. Rodgers, and R. C. Gentry, 1986: The relationship between satellite measured convective bursts and tropical cyclone intensification. Mon. Wea. Rev., 114, 1539-1546, doi:10.1175/ 1520-0493(1986) $114<1539$ :TRBSMC $>2.0$. CO; 2 .

Stern, D. P., and D. S. Nolan, 2009: Reexamining the vertical structure of tangential winds in tropical cyclones: Observations and theory. J. Atmos. Sci., 66, 3579-3600, doi:10.1175/ 2009JAS2916.1.
Stevenson, S. N., and K. L. Corbosiero, 2016: Understanding the relationship between lightning outbreaks and tropical cyclone intensity change. 32nd Conf. on Hurricanes and Tropical Meteorology, San Juan, PR, Amer. Meteor. Soc., 5D.3. [Available online at https://ams.confex.com/ams/32Hurr/webprogram/ Paper293200.html.]

,-- , and J. Molinari, 2014: The convective evolution and rapid intensification of Hurricane Earl (2010). Mon. Wea. Rev., 142, 4364-4380, doi:10.1175/MWR-D-14-00078.1.

$\longrightarrow, \ldots$, and S. F. Abarca, 2016: Lightning in eastern North Pacific tropical cyclones: A comparison to the North Atlantic. Mon. Wea. Rev., 144, 225-239, doi:10.1175/MWR-D-15-0276.1; Corrigendum. 144, 4483-4485, doi:10.1175/MWR-D-16-0283.1.

Velden, C. S., T. L. Olander, and R. M. Zehr, 1998: Development of an objective scheme to estimate tropical cyclone intensity from digital geostationary satellite infrared imagery. Wea. Forecasting, 13, 172-186, doi:10.1175/1520-0434(1998)013<0172: DOAOST $>2.0 . \mathrm{CO} ; 2$.

— , and Coauthors, 2006: The Dvorak tropical cyclone intensity estimation technique: A satellite-based method that has endured for over 30 years. Bull. Amer. Meteor. Soc., 87, 1195-1210, doi:10.1175/BAMS-87-9-1195.

Wilks, D. S., 2006: Statistical Methods in the Atmospheric Sciences. 2nd ed. Academic Press, 627 pp.

Zawislak, J., H. Jiang, G. R. Alvey III, E. J. Zipser, R. F. Rogers, J. A. Zhang, and S. N. Stevenson, 2016: Observations of the structure and evolution of Hurricane Edouard (2014) during intensity change. Part I: Relationship between the thermodynamic structure and precipitation. Mon. Wea. Rev., 144, 3333-3354, doi:10.1175/MWR-D-16-0018.1. 